\title{
Flu Vaccination Attitudes, Behaviours, and Knowledge among Health Workers
}

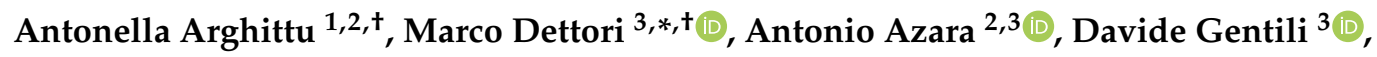 \\ Antonello Serra ${ }^{2}$, Bruno Contu ${ }^{2}$ and Paolo Castiglia $2,3, *$ (D) \\ 1 Department of Biomedical Sciences, University of Sassari, 07100 Sassari, Italy; arghittu.antonella@gmail.com \\ 2 University Hospital in Sassari, 07100 Sassari, Italy; azara@uniss.it (A.A.); antonello.serra@aousassari.it (A.S.); \\ bruno.contu@aousassari.it (B.C.) \\ 3 Department of Medical, Surgical and Experimental Sciences, University of Sassari, 07100 Sassari, Italy; \\ davide.gentili@aulss2.veneto.it \\ * Correspondence: madettori@uniss.it (M.D.); castigli@uniss.it (P.C.) \\ + These authors contributed equally to this work.
}

Received: 18 April 2020; Accepted: 2 May 2020; Published: 3 May 2020

check for updates

\begin{abstract}
The aim of this work is to evaluate the attitudes, behaviours, and knowledge of health workers employed at an Italian University Hospital on the topic of vaccinations and in regard to flu vaccination. To this end, the study provided for the articulation of a computerised questionnaire on the digital platform EUSurvey which was administered online via e-mail to a sample of 457 health workers, in the period between November 2018 and March 2019. The data were subjected to descriptive and inferential statistical analysis. In particular, a logistic regression analysis was carried out in order to evaluate the relationship between the variables collected and the dichotomous outcome (vaccinated/unvaccinated subjects in the 2018-2019 season). The results, in line with what has been reported by the literature, highlighted that vaccine hesitancy is prevalent also among health workers. Furthermore, according to our study, only $30.6 \%$ of the health care workers had the flu vaccination. The survey points out the need to plan educational and informative interventions aimed at changing the attitudes, behaviours, and knowledge of health workers in the field of flu vaccination, for the purpose of protecting the health of healthcare personnel and their patients.
\end{abstract}

Keywords: vaccination; health worker; flu vaccination; vaccine hesitancy

\section{Introduction}

Influenza syndrome is a significant public health problem and a major source of direct and indirect costs due to the management of cases and complications of the disease [1]. Globally, according to the World Health Organisation (WHO), the flu virus affects between 5\% and 15\% of the adult population every year (from 350 million to 1 billion people), with a mortality rate ranging from 250,000 to 500,000 deaths [1-3]. According to the European Centre for Disease Prevention and Control (ECDC), between 4 and 50 million people in Europe each year experience symptomatic flu with between 15,000 and 70,000 related deaths [4]. Ninety percent of deaths occur in subjects over the age of 65, especially among those with underlying chronic clinical conditions [5,6]. In Italy alone, 5-8 million people are affected by flu syndrome each year, the impact of which, in terms of lethality, translates to an estimated 8000 deaths per year $[7,8]$.

In public health, the prevention of seasonal flu is of utmost importance in order to reduce its epidemiological, clinical, and economic impact $[9,10]$. To date, vaccination is the most effective preventive strategy available for this purpose $[6,11]$. However, despite this important opportunity for prevention, the percentage of vaccinated individuals is constantly decreasing $[2,12]$. 
For the 2018/2019 season, the coverage values recorded in Italy show a percentage of $15.8 \%$, slightly higher than that of the previous season (15.3\% in the two-year period 2017-2018). In Sardinia, influenza vaccination coverage per 100 inhabitants is $14.2 \%[8,12]$.

With regard to the poor compliance with flu vaccination, numerous studies in the literature show that seasonal flu in a common sense represents a health event whose clinical and social impact is largely underestimated $[2,3,13,14]$.

The altered perception of the health risk, in this context, has a significant impact on health decisions made by the population; in fact, a discrepancy between real danger and perceived risk can lead to inappropriate behaviours that do not comply with the recommended public health measures [15]. According to the "outrage" theory coined by the American sociologist Peter Sandman [16], in the perception of risk, a key role is played by the emotional component surrounding the event.

Influenza is often perceived by the population as an exacerbated or an inapparent risk, compared to the real incidence of the disease [17-20]. What is more, several studies have shown that an inaccurate perception of the magnitude of an event is based on poor and ineffective risk communication [20-24].

The rampant phenomenon of vaccine hesitancy [25-28] highlights the need to focus attention on the complexity of the communication processes, which are indispensable for adequate adherence to vaccination. In fact, despite the various initiatives promoted at a national and international level, the spread of distorted information in the media and in particular on the various social networking sites has led to a decrease in vaccination coverage among healthcare workers also [28-32].

Healthcare workers are particularly exposed to the risk of contracting the flu (in a clinical and sub-clinical form) and also transmitting the infection to patients whose underlying conditions increase the risk of complications [2,33-36]. In the global healthcare landscape, in order to guarantee the protection of patients and the health workers themselves, the Centres of Disease Control and Prevention (CDC), the Advisory Committee on Immunization Practices (ACIP), and the Healthcare Infection Control Practices Advisory Committee (HICPAC) annually recommend anti-influenza vaccination to all healthcare professionals [35-37]. In the United States, to optimise the control of influenza in the healthcare environment, the "Healthy People 2020" plan was released, establishing a minimum target of $90 \%$ flu vaccination coverage among health workers by 2020 [38].

In Europe, all EU member states have adhered to a minimum target of $75 \%$ and the Italian Ministry of Health, in line with what has been established in Europe, has set a minimum threshold of $75 \%$ coverage (given the optimal value of 95\%) [39,40]; to this end, vaccination is offered actively and free-of-charge to health workers, as well as to all individuals aged sixty-five and over, as well as to the at-risk categories provided for by the 2017-2019 National Vaccination Prevention Plan (Piano Nazionale di Prevenzione Vaccinale) [41]. Nonetheless, coverage for influenza vaccination among healthcare workers falls short of the minimum targets set.

Based on these premises, the present work aims to evaluate the relationship between the knowledge, attitudes, and behaviours of healthcare professionals and their propensity towards flu vaccination, in order to understand which phenomena are most implicated in vaccine hesitancy and to develop targeted strategies to increase vaccination coverage and improve compliance among health workers. To the best of our knowledge, this is the first study to focus on the flu vaccination attitude, behaviours, and knowledge among healthcare workers in Sardinia, Italy.

\section{Materials and Methods}

\subsection{Study Setting}

The present study did not require ethical approval for its observational design according to the Italian law (Gazzetta Ufficiale no. 76 dated 31.3.2008).

The fact-finding survey was directed towards employees of the University Hospital of Sassari (AOU-SS). The AOU-SS is the main hospital in Sardinia for the number and heterogeneity of its 
professional resources (2710 employees as of 01.12.2018) and its technological resources and carries out multi-specialist activities of care, teaching, and research for the entire northern territory of Sardinia.

The organisational structure of the hospital is set out in the corporate deed (art. 3 paragraph 1 bis of Legislative Decree no. 502/92 and subsequent amendments), which identifies a total of 77 operational units. Based on the type of activity carried out, these units are grouped into macro-areas: 29 medical areas; 18 surgical areas; 30 services/other [42].

\subsection{Survey Method}

An anonymous self-administered questionnaire was developed on the EUSurvey digital platform (an open-source tool of the European Commission for the construction of surveys and consultations). The questionnaire was tested, adjusted, and validated through a pilot study, carried out on a convenience sample of 40 experts in public health. The internal consistency was assessed with Cronbach's alpha test.

To assess the attitudes, behaviours, and knowledge of the AOU-SS staff regarding flu vaccination, the questionnaire was divided into 26 close-ended mandatory questions divided into 4 areas of investigation: 6 personal data questions aimed at classifying the professional profile of the participants; 7 questions related to attitudes; 3 questions about behaviours, and 10 questions about knowledge. For questionnaire compilation, it was compulsory to answer each question.

The questionnaire was administered by sending a URL code via e-mail to AOU-SS employees in the period between November 2018 and March 2019. The general information of the respondents is shown in Table 1. The attitudes, behaviours, and knowledge questions are shown in Table 2 (Results Section). In particular, the questions and the close-ended answers (coded as qualitative data) are reported in the first and second columns of the table, respectively.

Table 1. Participants' general information.

\begin{tabular}{|c|c|c|}
\hline General Information & Answers (Yes/No) & Yes $(\%)$ \\
\hline 1. Gender & Male & $168 / 457(36.8)$ \\
\hline \multirow{5}{*}{ 2. Age (years) } & $25-34$ & $37 / 457(8.1)$ \\
\hline & $35-44$ & $102 / 457(22.3)$ \\
\hline & $45-54$ & $167 / 457(36.5)$ \\
\hline & $55-64$ & $143 / 457(31.3)$ \\
\hline & $>65$ & $8 / 457(1.8)$ \\
\hline \multirow{3}{*}{ 3. Job } & Physician & $163 / 457(35.7)$ \\
\hline & Nurse & $178 / 457(38.9)$ \\
\hline & Other & $116 / 457(25.4)$ \\
\hline \multirow{3}{*}{ 4. Area } & Medical & $151 / 457(33.0)$ \\
\hline & Surgical & $106 / 457(23.2)$ \\
\hline & Service/other & $200 / 457(43.8)$ \\
\hline \multirow{4}{*}{ 5. Seniority (years of service) } & $0-9$ & $110 / 457(24.1)$ \\
\hline & $10-19$ & $129 / 457(28.2)$ \\
\hline & $20-29$ & $156 / 457(34.1)$ \\
\hline & $>30$ & $62 / 457(13.6)$ \\
\hline \multirow{4}{*}{$\begin{array}{l}\text { 6. Contact time (\% working time } \\
\text { spent in contact with the patient) }\end{array}$} & $0-25$ & $95 / 457(20.8)$ \\
\hline & $26-50$ & $49 / 457(10.7)$ \\
\hline & $51-75$ & 90/457 (19.7) \\
\hline & $76-100$ & $223 / 457(48.8)$ \\
\hline
\end{tabular}




\subsection{Statistical Analysis}

Data were entered on Excel (Microsoft Office, Microsoft Corporation, Redmond, WA, USA) and analysed using the STATA software 11 (StatCorp., Austin, TX, USA) and MedCalc (MedCalc Software Ltd., Ostend, Belgium). Qualitative variables were summarised with absolute and relative (percentage) frequencies.

Logistic regression analyses were performed to assess the relationship between the outcome (vaccination carried out in 2018-2019) and variables related to health workers' attitudes, behaviours, and knowledge. The outcome was established by attributing a value of 1 if the participant underwent vaccination in 2018-2019, and a value of 0 otherwise. Only the variables that were significant in the first phase of univariate analysis were included in the multivariate model.

A two-tailed $p$-value of less than 0.05 was considered statistically significant.

\section{Results}

The invitation to participate in the compilation of the questionnaire was sent via e-mail to 2270 (83.7\%) AOU-SS health workers. There were 457 (20.1\%) questionnaires completed and returned.

Cronbach's alpha reliability test showed a global value of 0.8592 , which highlights the good internal consistency of the questionnaire.

The results of the descriptive analysis are shown in Table 2.

Table 2. Descriptive analysis of the variables inherent to the health workers' general information, attitudes, behaviours, and knowledge. The first column on the left shows the questions of the questionnaire, while the possible answers (yes/no) are shown in the "answers" column.

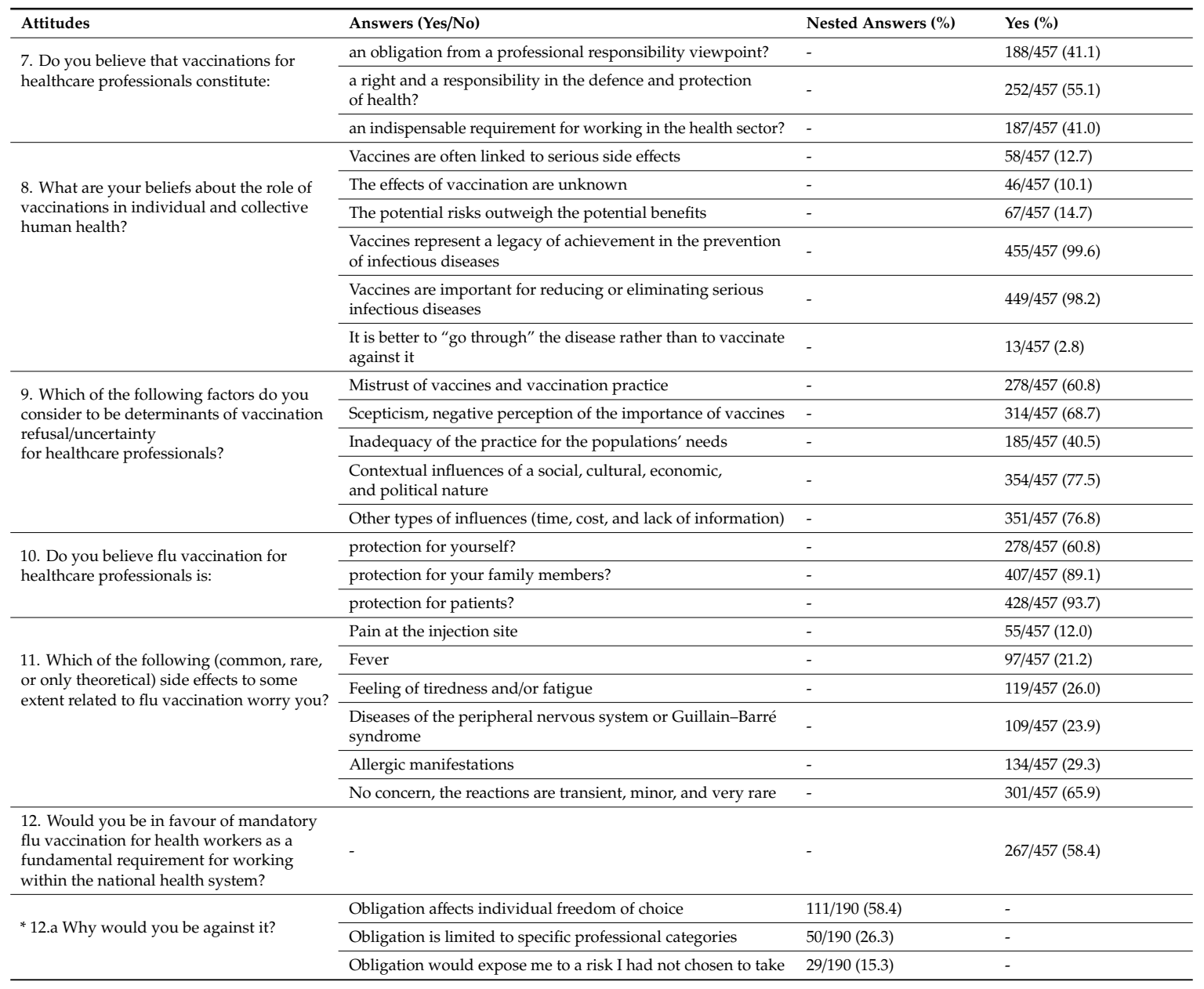


Table 2. Cont.

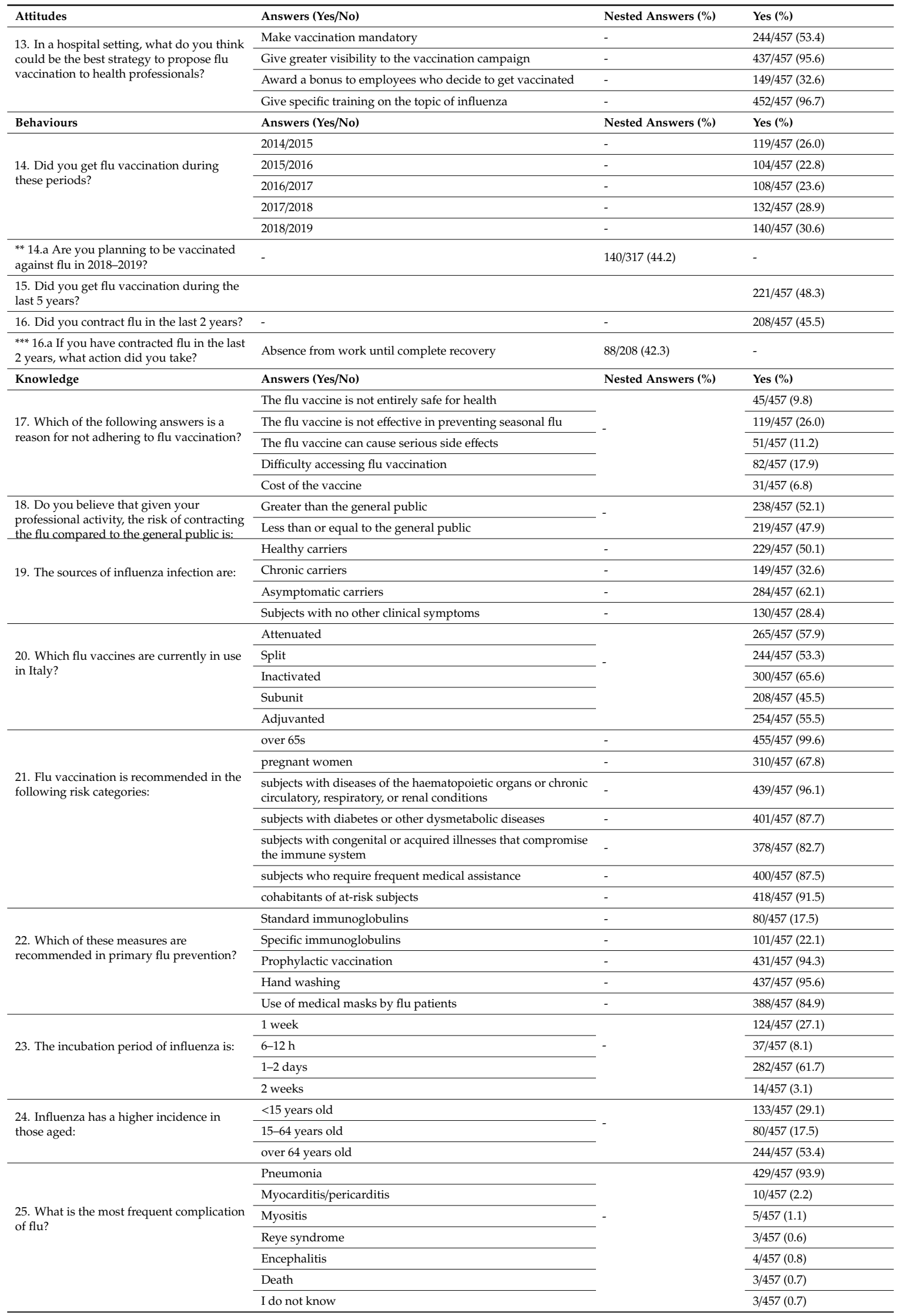


Table 2. Cont.

\begin{tabular}{|c|c|c|c|}
\hline Knowledge & Answers (Yes/No) & Nested Answers (\%) & Yes (\%) \\
\hline \multirow{3}{*}{$\begin{array}{l}\text { 26. The influenza vaccines in use protect } \\
\text { against viruses of type: }\end{array}$} & $A$ and $B$ & & $260 / 457(56.9)$ \\
\hline & only A & & $49 / 457$ (10.7) \\
\hline & $\mathrm{A}, \mathrm{B}$, and $\mathrm{C}$ & & $148 / 457(32.4)$ \\
\hline
\end{tabular}

* Question 12.a was made accessible only to those who gave a negative answer to question no. 12, thus excluding those who gave affirmative answers (nested answers). ** Question 14.a was made accessible only to those who gave a negative answer to question no. 14, thus excluding those who gave affirmative answers (nested answers). ${ }^{* * *}$ Question 16.a was made accessible only to those who gave a negative answer to question no. 16, thus excluding those who gave affirmative answers (nested answers).

\subsection{Attitudes}

Of those interviewed, 55.1\% believed that flu vaccination for health workers was a right and a responsibility in the protection of health. In addition, almost all respondents believed that vaccines were a pivotal tool for prevention and were capable of eliminating serious communicable diseases (99.6\% and 98.2\%, respectively). Moreover, the same interviewees considered anti-influenza vaccination for health workers as protection for patients (93.7\%), and most (65.9\%) showed no concern about the possible side effects of vaccination. As such, $58.4 \%$ of respondents were in favour of mandatory flu vaccination for health workers, while the majority of those not in favour (111 out of 190 respondents) believed that obligation affected individual freedom of choice. Finally, giving greater visibility to the vaccination campaign, together with a specific training activity on the topic of influenza, were considered the best strategies for proposing the flu vaccination to healthcare professionals by almost all interviewees $(95.6 \%$ and $96.7 \%$, respectively).

\subsection{Behaviours}

As regards the behaviour of the sample interviewed about flu vaccination, the highest percentage of vaccinated subjects (30.6\%) regarding the five years observed, was attributable to the 2018/2019 season. Moreover, $44.2 \%$ of those unvaccinated in 2018/2019, stated they wished to be vaccinated. What is more, almost half $(48.3 \%)$ of the respondents stated they had been vaccinated in the past 5 years. At the same time, $45.5 \%$ stated they had contracted flu during the past 2 years; of these only $42.3 \%$ of cases were absent from work until they had made a complete recovery.

\subsection{Knowledge}

Knowledge among those interviewed concerning flu vaccination showed that, albeit in a low percentage $(26.0 \%)$, the ineffectiveness in the prevention of seasonal flu was the main reason for failing to adhere to vaccination. Only $52.1 \%$ of the respondents were aware of having a greater risk of contracting the disease than the general public, while almost all were aware that there are some at-risk categories, such as those aged over 65 (99.6\%) and people with dysmetabolic diseases and diabetes $(87.7 \%)$. Only $27.1 \%$ were aware of the actual incubation period of the disease, just as only $29.1 \%$ were aware that the incidence of influenza is higher among subjects $<15$ years old. By contrast, almost all respondents (93.9\%) knew that pneumonia was the most frequent complication of influenza, and more than half $(56.9 \%)$ knew that the vaccines currently in use protect against type A and type B viruses.

\subsection{Logistic Regression Analysis}

As regards the univariate and multivariate analysis, the variables relating to questions number 14 and 15 were excluded from the analysis, as all the respondents who were vaccinated in 2018-2019 (outcome) had received flu vaccination also in the last 5 years (at least once). Thus, this led to the exclusion from the model of the variables associated with the outcome due to the obvious collinearity. In the models, the questions relating to knowledge were categorised based on the correctness or otherwise of the answer given (correct answer $=1$, otherwise $=0$ ). The questions with nested answers 
were excluded from the inferential analysis, as they refer to a limited number of respondents and, therefore, are not representative of the sample as a whole. The results are shown in Table 3.

No significant differences were observed for age, gender, and seniority with regard to the knowledge level of the respondents.

The variables that were statistically significant from the univariate analysis in relation to the outcome (staff vaccinated in the 2018-2019 season) were selected and included in a multivariate logistic regression model (Figure 1).

Following multivariate inferential analysis, some variables were found to be associated with the outcome. In particular, AOU-SS health workers showed a greater propensity to flu vaccination if: (i) doctors (odds ratio, OR (confidence interval, CI 95\%) $=2.6(1.3-5.2) ; p=0.007$ ); (ii) in favour of mandatory flu vaccination for their professional category (OR (CI 95\%) $=3.0(1.3-6.9) ; p=0.011$; (iii) aware of their greater risk of developing the disease than that of the general population (OR (CI 95\%) $=2.5(1.5-4.3) ; p=0.001)$; (iv) are aware that some categories of people (pregnant women, OR (CI 95\%) $2.0(1.1-3.6) ; p=0.018$, subjects with diabetes or dysmetabolic diseases, OR (CI 95\%) $=3.1(1.0-9.2)$; $p=0.043)$ are at-risk categories. On the other hand, the health workers who did not get flu vaccination in the 2018-2019 season were those who: i) belonged to the surgical area (OR (CI 95\%) $=0.4(0.2-0.8)$; $p=0.010)$; ii) spent more time in contact with patients (OR (CI 95\%) $=0.7(0.6-0.9) ; p=0.005)$; iii) declared difficulties in accessing vaccination (OR (CI 95\%) $=0.3(0.2-0.7) ; p=0.002)$. 
Table 3. Univariate and multivariate analysis evaluating the relationships between the independent variables and the outcome vaccinated/unvaccinated subjects in the 2018-2019 season.

\begin{tabular}{|c|c|c|c|c|c|}
\hline Questionnaire Area (Item No.) & Answers & Univariate Analysis & & Multivariate Analysis & \\
\hline General Information & (Yes/No) & Odds Ratio $(95 \% \mathrm{CI})$ & $p$-Value & Odds Ratio (95\% CI) & $p$-Value \\
\hline 1. Gender & Male & $2.1(1.4-3.2)$ & 0.000 & $1.5(0.9-2.6)$ & 0.108 \\
\hline \multirow{5}{*}{ 2. Age (years) } & $25-34$ & \multirow{5}{*}{$1.2(1.0-1.5)$} & \multirow{5}{*}{0.071} & \multirow{5}{*}{-} & \multirow{5}{*}{-} \\
\hline & $35-44$ & & & & \\
\hline & $45-54$ & & & & \\
\hline & $55-64$ & & & & \\
\hline & $>65$ & & & & \\
\hline \multirow{3}{*}{ 3. Job } & Physician & $2.6(1.7-4.0)$ & 0.000 & $2.6(1.3-5.2)$ & 0.007 \\
\hline & Nurse & $0.4(0.3-0.7)$ & 0.000 & $1.2(0.6-2.5)$ & 0.578 \\
\hline & Other & $0.8(0.5-1.2)$ & 0.291 & - & - \\
\hline \multirow{3}{*}{ 4. Area } & Medical & $1.3(0.9-2.0)$ & 0.216 & - & - \\
\hline & Surgical & $0.4(0.2-0.7)$ & 0.002 & $0.4(0.2-0.8)$ & 0.010 \\
\hline & Service/other & $1.4(0.9-2.1)$ & 0.114 & - & - \\
\hline \multirow{4}{*}{ 5. Seniority (years of service) } & $0-9$ & \multirow{4}{*}{$1.1(0.9-1.4)$} & \multirow{4}{*}{0.187} & \multirow{4}{*}{-} & \multirow{4}{*}{-} \\
\hline & $10-19$ & & & & \\
\hline & $20-29$ & & & & \\
\hline & $>30$ & & & & \\
\hline \multirow{4}{*}{$\begin{array}{l}\text { 6. Contact time (\% working time spent in contact with } \\
\text { the patient) }\end{array}$} & $0-25$ & \multirow{4}{*}{$0.8(0.7-0.9)$} & \multirow{4}{*}{0.009} & \multirow{4}{*}{$0.7(0.6-0.9)$} & \multirow{4}{*}{0.005} \\
\hline & $26-50$ & & & & \\
\hline & $51-75$ & & & & \\
\hline & $76-100$ & & & & \\
\hline Attitudes & (Yes/No) & OR $(95 \% \mathrm{CI})$ & $p$-Value & OR $(95 \% \mathrm{CI})$ & $p$-Value \\
\hline \multirow{3}{*}{$\begin{array}{l}\text { 7. Do you believe that vaccinations for healthcare } \\
\text { professionals constitute: }\end{array}$} & an obligation from a professional responsibility viewpoint? & $2.9(1.4-5.8)$ & 0.004 & $1.1(0.4-2.9)$ & 0.790 \\
\hline & a right and a responsibility in the defence and protection of health? & $3.9(0.9-17.2)$ & 0.071 & - & - \\
\hline & an indispensable requirement for working in the health sector? & $4.4(2.1-9.1)$ & 0.000 & $1.8(0.7-4.9)$ & 0.244 \\
\hline \multirow{6}{*}{$\begin{array}{l}\text { 8. What are your beliefs about the role of vaccinations } \\
\text { in individual and collective human health? }\end{array}$} & Vaccines are often linked to serious side effects & $0.6(0.3-1.2)$ & 0.149 & - & - \\
\hline & The effects of vaccination are unknown & $0.4(0.2-0.9)$ & 0.021 & $0.8(0.3-2.3)$ & 0.739 \\
\hline & The potential risks outweigh the potential benefits & $0.7(0.4-1.2)$ & 0.196 & - & - \\
\hline & $\begin{array}{l}\text { Vaccines represent a legacy of achievement in the prevention of } \\
\text { infectious diseases }\end{array}$ & $\begin{array}{l}\text { Omitted due to } \\
\text { collinearity }\end{array}$ & - & - & - \\
\hline & $\begin{array}{l}\text { Vaccines are important for reducing or eliminating serious infectious } \\
\text { diseases }\end{array}$ & $3.1(0.4-25.8)$ & 0.287 & - & - \\
\hline & It is better to "go through" the disease rather than to vaccinate against it & $0.7(0.2-2.5)$ & 0.551 & - & - \\
\hline
\end{tabular}


Table 3. Cont

\begin{tabular}{|c|c|c|c|c|c|}
\hline Questionnaire Area (Item No.) & Answers & Univariate Analysis & & Multivariate Analysis & \\
\hline General Information & (Yes/No) & Odds Ratio $(95 \% \mathrm{CI})$ & $p$-Value & Odds Ratio (95\% CI) & $p$-Value \\
\hline \multirow{5}{*}{$\begin{array}{l}\text { 9. Which of the following factors do you consider to } \\
\text { be determinants of vaccination refusal/uncertainty for } \\
\text { healthcare professionals? }\end{array}$} & Mistrust of vaccines and vaccination practice & $1.1(0.7-1.6)$ & 0.703 & - & - \\
\hline & Scepticism, negative perception of the importance of vaccines & $1.2(0.8-1.9)$ & 0.405 & - & - \\
\hline & Inadequacy of the practice with respect to the populations' needs & $0.6(0.4-0.9)$ & 0.016 & $0.7(0.4-1.2)$ & 0.184 \\
\hline & Contextual influences of a social, cultural, economic, and political nature & $1.4(0.9-2.3)$ & 0.179 & - & - \\
\hline & Other types of influences (time, cost, and lack of information) & $1.1(0.7-1.8)$ & 0.723 & - & - \\
\hline \multirow{3}{*}{$\begin{array}{l}\text { 10. Do you believe flu vaccination for healthcare } \\
\text { professionals is: }\end{array}$} & protection for yourself? & $5.5(1.9-15.6)$ & 0.001 & $1.5(0.3-7.5)$ & 0.639 \\
\hline & protection for your family members? & $7.9(2.4-26.0)$ & 0.001 & $2.4(0.5-11.7)$ & 0.266 \\
\hline & protection for patients? & Omitted due collinearity & - & - & - \\
\hline \multirow{6}{*}{$\begin{array}{l}\text { 11. Which of the following (common, rare, or only } \\
\text { theoretical) side effects to some extent related to flu } \\
\text { vaccination worry you? }\end{array}$} & Pain at the injection site & $1.0(0.6-19)$ & 0.962 & - & - \\
\hline & Fever & $0.6(0.3-0.9)$ & 0.032 & $1.3(0.6-2.8)$ & 0.478 \\
\hline & Feeling of tiredness and/or fatigue & $0.4(0.3-0.7)$ & 0.001 & $0.6(0.3-1.2)$ & 0.138 \\
\hline & Diseases of the peripheral nervous system or Guillain-Barré syndrome & $1.0(0.7-1.6)$ & 0.885 & - & - \\
\hline & Allergic manifestations & $0.8(0.5-1.2)$ & 0.261 & - & - \\
\hline & No concern, the reactions are transient, minor, and very rare & $1.8(1.1-2.7)$ & 0.012 & $1.4(0.8-2.5)$ & 0.202 \\
\hline $\begin{array}{l}\text { 12. Would you be in favour of mandatory flu } \\
\text { vaccination for health workers as a fundamental } \\
\text { requirement for working within the national health } \\
\text { system? }\end{array}$ & - & $4.4(2.8-7.1)$ & 0.000 & $3.0(1.3-6.9)$ & 0.011 \\
\hline \multirow{4}{*}{$\begin{array}{l}\text { 13. In a hospital setting, what do you think could be } \\
\text { the best strategy to propose flu vaccination to health } \\
\text { professionals? }\end{array}$} & Make vaccination mandatory & $3.5(2.2-5.4)$ & 0.000 & $0.8(0.4-1.8)$ & 0.585 \\
\hline & Give greater visibility to the vaccination campaign & $4.2(0.9-18.2)$ & 0.058 & - & - \\
\hline & Award a bonus to employees who decide to get vaccinated & $1.7(1.1-2.5)$ & 0.014 & $1.5(0.9-2.6)$ & 0.114 \\
\hline & Give specific training on the topic of influenza & $1.8(0.5-6.5)$ & 0.370 & - & - \\
\hline Behaviours & (Yes/No) & OR $(95 \% \mathrm{CI})$ & $p$-Value & OR $(95 \% \mathrm{CI})$ & $p$-Value \\
\hline 16. Did you get influenza in the last 2 years? & - & $1.1(0.7-1.6)$ & 0.794 & - & - \\
\hline Knowledge & (Yes/No) & OR $(95 \% \mathrm{CI})$ & $p$-Value & OR $(95 \% \mathrm{CI})$ & $p$-Value \\
\hline \multirow{5}{*}{$\begin{array}{l}\text { 17. Which of the following answers is a reason for not } \\
\text { adhering to flu vaccination? }\end{array}$} & The flu vaccine is not entirely safe for health & $1.4(0.8-2.7)$ & 0.275 & - & - \\
\hline & The flu vaccine is not effective in preventing seasonal flu & $0.5(0.3-0.8)$ & 0.002 & $1.3(0.7-2.5)$ & 0.436 \\
\hline & The flu vaccine can cause serious side effects & $1.8(0.6-1.9)$ & 0.903 & - & - \\
\hline & Difficulty accessing flu vaccination & $0.5(0.3-0.9)$ & 0.034 & $0.3(0.2-0.7)$ & 0.002 \\
\hline & Cost of the vaccine & $0.6(0.3-1.5)$ & 0.317 & - & - \\
\hline $\begin{array}{l}\text { 18. Do you believe that given your professional } \\
\text { activity, the risk of contracting the flu compared to the } \\
\text { general public is: }\end{array}$ & Greater & $3.1(2.1-4.8)$ & 0.000 & $2.5(1.5-4.3)$ & 0.001 \\
\hline
\end{tabular}


Table 3. Cont

\begin{tabular}{|c|c|c|c|c|c|}
\hline Questionnaire Area (Item No.) & Answers & Univariate Analysis & & Multivariate Analysis & \\
\hline \multirow{4}{*}{ 19. The sources of influenza infection are: } & Healthy carriers & $1.2(0.8-1.7)$ & 0.435 & - & - \\
\hline & Chronic carriers & $0.7(0.4-1.1)$ & 0.099 & - & - \\
\hline & Asymptomatic carriers & $1.2(0.8-1.9)$ & 0.296 & - & - \\
\hline & Subjects with no other clinical symptoms & $1.2(0.8-1.7)$ & 0.462 & - & - \\
\hline 20. Which flu vaccines are currently in use in Italy? & Attenuated & $1.4(0.9-2.0)$ & 0.140 & - & - \\
\hline \multirow{7}{*}{$\begin{array}{l}\text { 21. Flu vaccination is recommended in the following } \\
\text { risk categories: }\end{array}$} & Over 65s & Omitted due collinearity & - & - & - \\
\hline & Pregnant women & $2.7(1.7-4.4)$ & 0.000 & $2.0(1.1-3.6)$ & 0.018 \\
\hline & $\begin{array}{l}\text { subjects with diseases of the haematopoietic organs or chronic } \\
\text { circulatory, respiratory, or renal conditions }\end{array}$ & $3.7(0.8-16.2)$ & 0.086 & - & - \\
\hline & subjects with diabetes or other dysmetabolic diseases & $5.2(2.0-13.3)$ & 0.001 & $3.1(1.0-9.2)$ & 0.043 \\
\hline & $\begin{array}{l}\text { subjects with a congenital or acquired illness which compromise the } \\
\text { immune system }\end{array}$ & $1.3(0.7-2.2)$ & 0.391 & - & - \\
\hline & subjects who require frequent medical assistance & $2.6(1.2-5.5)$ & 0.012 & $1.1(0.4-2.7)$ & 0.918 \\
\hline & cohabitants of at-risk subjects & $2.6(1.1-6.3)$ & 0.037 & $1.1(0.4-3.5)$ & 0.826 \\
\hline \multirow{5}{*}{$\begin{array}{l}\text { 22. Which of these measures are recommended in } \\
\text { primary flu prevention? }\end{array}$} & Standard immunoglobulins & $1.6(0.9-2.9)$ & 0.084 & - & - \\
\hline & Specific immunoglobulins & $1.7(0.9-2.8)$ & 0.054 & - & - \\
\hline & Prophylactic vaccination & $3.6(1.1-12.1)$ & 0.041 & $3.4(0.8-13.9)$ & 0.089 \\
\hline & Hand washing & $1.3(0.5-3.8)$ & 0.577 & - & - \\
\hline & Use of medical masks by flu patients & $0.7(0.4-1.2)$ & 0.170 & - & - \\
\hline 23. The incubation period of influenza is: & 1 week & $1.4(0.9-2.2)$ & 0.110 & - & - \\
\hline 24. Influenza has a higher incidence in those aged: & $<15$ years old & $1.6(1.0-2.4)$ & 0.039 & $1.3(0.8-2.3)$ & 0.303 \\
\hline 25. What is the most frequent complication of flu? & Pneumonia & $1.1(0.5-2.7)$ & 0.807 & - & - \\
\hline $\begin{array}{l}\text { 26. The influenza vaccines in use protect against } \\
\text { viruses of type: }\end{array}$ & $A$ and $B$ & $1.4(0.9-2.1)$ & 0.088 & - & - \\
\hline
\end{tabular}




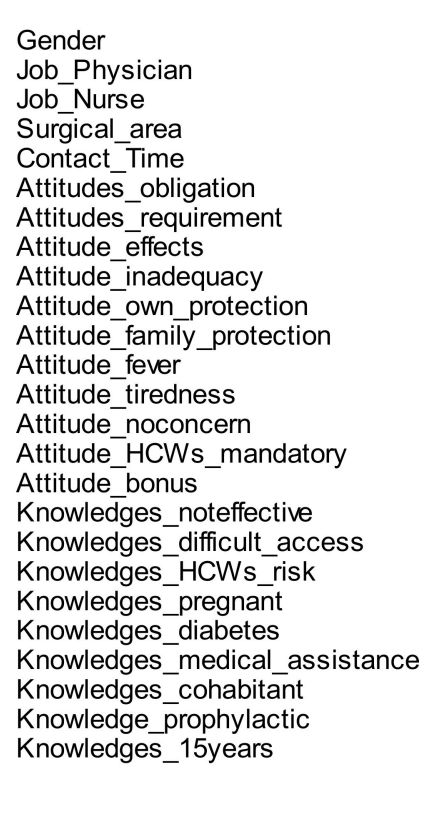

Job_Physician

Job-Nurse

Surgical_area

Attitudes obligation

Attitudes requirement

Attitude_effects

Attitude_inadequacy

Attitude_fever

Attitude tirednes

Attitude noconcer

Attitude_HCWs_mandatory

Knowledges_difficult_acces

Knowledges_HCWs_risk

Knowledges pregnant

Knowledges diabetes

Knowledges_medical_assistance

nowledges cohabitant

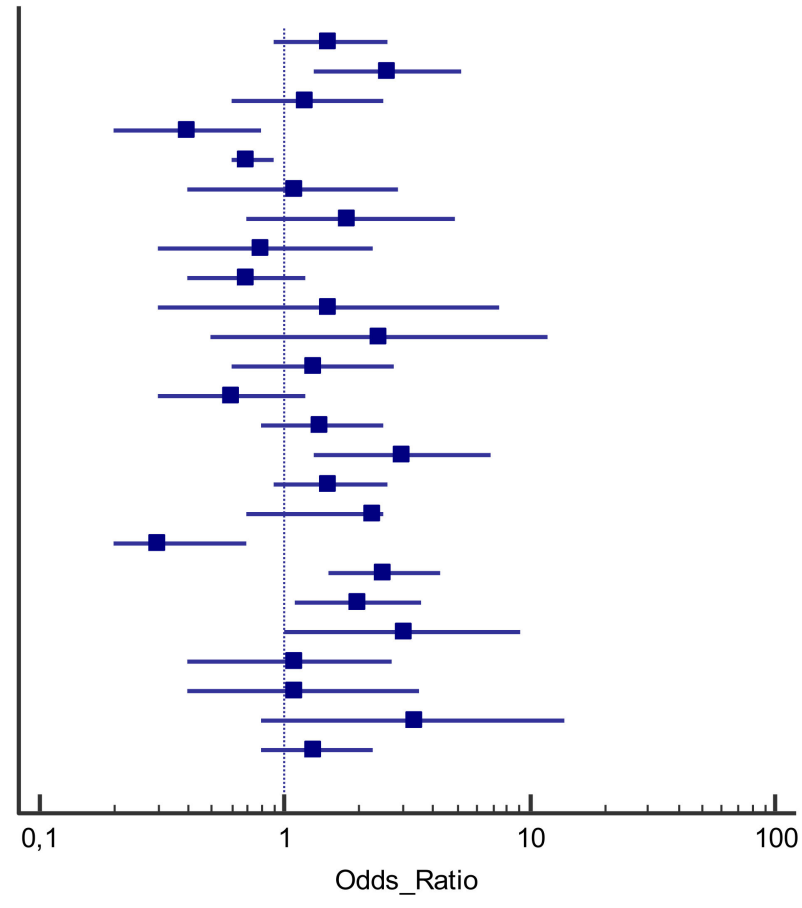

Figure 1. Forest plot reporting the multivariate logistic analysis results; odds ratios and $95 \%$ confidence intervals (question_answer) concerning the observed outcome (vaccinated/unvaccinated subjects in the 2018-2019 season).

\section{Discussion}

The present study presents weaknesses and strengths that are discussed below. In particular, although the survey provided for the administration of a questionnaire to 2270 AOU-SS employees, only 457 questionnaires were returned (20.1\%). Therefore, this could underlie a selection bias, because those who are most attentive to vaccination also are those who most likely respond to an interview on it. However, the sample that took part in the survey was mainly made up of healthcare workers who are in direct contact with patients $(68.5 \%$ of the interviewees spent over $50 \%$ of their time in contact with the patient) and that, even if counterintuitive, according to the results from the logistic regression, should be those that less frequently get the flu vaccination. Therefore, these two phenomena, the former in favour and the latter against the vaccination compliance, tend to compensate each other. As a result, 30.6\% of respondents stated they had been vaccinated in the current season (2018-2019). This percentage was the highest of the years observed and, although there are no official statistics on the matter, it was greater than the vaccination coverage reported by the most recent observations at national and European level [43-46]. Furthermore, adding the number of respondents vaccinated in 2018-2019 to the number who expressed willingness to be vaccinated, the forecast of vaccination coverage of the sample observed rose to $60.2 \%$. This data suggests that the health workers who took part in the survey were highly inclined towards flu vaccination.

Despite potential selection bias, the results that emerged from the inferential analysis are in line with what has been observed in the literature by numerous other authors. For example, as has been found in recent observations, our results showed a significantly higher adhesion to vaccination by medical personnel [46-51]. On the contrary, staff working in the surgical area, as well as health workers who spent more time in contact with the patients, showed a lower adhesion to vaccination, which was also statistically significant. This result, found in other observations [52-54], is key to the implementation of targeted corrective measures.

As regards the results of the inferential analysis relating to the attitudes of the interviewees, our study, as mentioned, is in line with what has been observed by other authors internationally [47]. 
In particular, those who declared that they were vaccinated in 2018-2019, were in favour of mandatory influenza vaccination for healthcare professionals. It is interesting to note that most of those who were not in favour of mandatory vaccination believed that this obligation affected individual freedom of choice. Freedom of choice represents one of the main known determinants of vaccine hesitancy among health workers $[27,30]$.

The survey also significantly revealed that those who adhered to vaccination were aware of a greater risk of their developing the disease than the general public, and knew the higher risks of certain categories of people (subjects with dysmetabolic diseases or diabetes; pregnant women). It was in line with what has already been observed by other scholars [55].

A noteworthy result regarded the significant difficulty declared by the health workers for easy access to the vaccination service. This aspect is crucial for the development of intervention strategies, which must facilitate access to the service in order to increase coverage [56].

There is also the potential for social desirability bias, as the study participants may have overstated that they are prone to get the flu vaccine to appear more health conscious. However, "threat of disclosure", pertaining to respondents' concerns about possible risks, costs, or negative consequences of truthfully reporting a sensitive behaviour was limited by the anonymity and confidentiality of the digital survey administered, thus decreasing the respondent's concerns in admitting to some taboo (e.g., via confidentiality assurances or clever wording and framing of the sensitive item) [57-59].

\section{Conclusions}

In the context of social care, health workers are not exempt from the phenomenon of vaccine hesitancy, which is widespread also in the hospital setting. Immunising health professionals means, on the one hand, protecting the workers and the patients in their care, and on the other, curtailing the spread of infections, while maintaining a high quality of health and care services during epidemics.

Despite being offered actively and free of charge, the anti-influenza vaccination coverage of healthcare professionals continues to remain far below the minimum targets set. To counter this phenomenon, it will be essential to promote communication/information strategies tailored to healthcare professionals. These must be contextually supported by the provision of vaccination directly in the ward in order to overcome the difficulties of access to the service manifested by the respondents. The scheduling of interventions to promote influenza vaccination aimed at susceptible cohorts (e.g., surgical staff and non-medical staff) would enable an increase in vaccination coverage. Indeed, this affirmation is confirmed by the results that emerged regarding the knowledge of the staff interviewed. The results obtained, reveal that opinion tends to be favourable towards vaccination, with clear margins for improvement in terms of attitudes, knowledge, and behaviours and, thus, vaccine compliance.

Furthermore, as the occupational physicians (Ophs) are fundamental to inform the workers about the pros and cons of recommended vaccinations, an interaction with an Oph is also useful to address personal misconceptions and target false beliefs, ultimately increasing the awareness of the potential of the flu vaccine. For this reason, during the last two years, we have worked closely with Ophs to improve adherence to flu vaccination, focusing mainly on improving information (with many field events supported by the vaccinarsinsardegna.org team and also involving the basketball team Dinamo Sassari as a testimonial) and expanding the vaccine distribution network (vaccination in the hospital wards) $[60,61]$.

To conclude, although the vaccination coverage targets set at the national level are still distant, the present work highlights which strategies should be implemented to aim for the minimum values foreseen in the near future. The low questionnaire response rate suggested that who more likely responded to the questionnaire were in favour of flu vaccination. Consequently, the vaccination propensity among the healthcare workers we observed might be even lower than expected.

On the other hand, the actual Covid-19 pandemic could represent an opportunity of fighting the vaccine hesitancy propensity among Italian healthcare workers and AOU-SS healthcare professionals heavily hit by the virus. 
Author Contributions: Conceptualization, A.A. (Antonella Arghitt)., M.D. and P.C.; data curation, M.D., D.G., A.S. and P.C.; formal analysis, A.A. (Antonella Arghitt), M.D., A.A. (Antonio Azara) and P.C.; funding acquisition, P.C.; investigation, A.A. (Antonella Arghitt), M.D., A.A. (Antonio Azara), D.G., A.S., B.C. and P.C.; methodology, A.A. (Antonella Arghitt), M.D., A.A. (Antonio Azara), B.C. and P.C.; software, M.D. and P.C.; supervision, P.C.; validation, B.C.; writing-original draft, A.A. (Antonella Arghitt), M.D., A.A. (Antonio Azara) and D.G.; writing-review and editing, P.C. All authors have read and agreed to the published version of the manuscript.

Funding: This study was supported by "Fondo di Ateneo per la Ricerca 2019", University of Sassari.

Acknowledgments: The authors would like to thank Emma Dempsey for the English Language revision.

Conflicts of Interest: The authors declare no conflict of interest.

\section{References}

1. World Health Organization. Influenza. Global Influenza Program. Available online: http://www.who.int/ influenza/en/ (accessed on 18 February 2020).

2. World Health Organization. Influenza. Global Influenza Strategy 2019-2030. Available online: https: //www.who.int/influenza/global_influenza_strategy_2019_2030/en/(accessed on 18 February 2020).

3. Iuliano, A.D.; Roguski, K.M.; Chang, H.H.; Muscatello, D.J.; Palekar, R.; Tempia, S.; Cohen, C.; Gran, J.M.; Schanzer, D.; Cowling, B.J.; et al. Estimates of global seasonal influenza-associated respiratory mortality: A modelling study. Lancet 2018, 391, 1285-1300. [CrossRef]

4. ECDC/WHO. Flu News Europe. Joint ECDC - WHO/Europe Weekly Influenza Update. Available online: https://flunewseurope.org/ (accessed on 18 February 2020).

5. Arghittu, A.; Dettori, M.; Masia, M.D.; Azara, A.; Dempsey, E.; Castiglia, P. Social deprivation indexes and anti-influenza vaccination coverage in the elderly in Sardinia, Italy, with a focus on the Sassari municipality. J. Prev. Med. Hyg. 2019, 59, E45-E50. [CrossRef]

6. Gasparini, R.; Amicizia, D.; Lai, P.L.; Rossi, S.; Panatto, D. Effectiveness of adjuvanted seasonal influenza vaccines (Inflexal $\mathrm{V}{ }^{\circledR}$ and Fluad ${ }^{\circledR}$ ) in preventing hospitalization for influenza and pneumonia in the elderly: A matched case-control study. Hum. Vaccin Immunother. 2013, 9, 144-152. [CrossRef] [PubMed]

7. Rosano, A.; Bella, A.; Gesualdo, F.; Acampora, A.; Pezzotti, P.; Marchetti, S.; Ricciardi, W.; Rizzo, C. Investigating the impact of influenza on excess mortality in all ages in Italy during recent seasons (2013/14-2016/17 seasons). Int. J. Infect. Dis. 2019, 88, 127-134. [CrossRef] [PubMed]

8. Ministero della Salute. Influenza. Sistema di Sorveglianza InfluNet. Available online: http://www.salute.gov.it/portale/influenza/dettaglioContenutiInfluenza.jsp?lingua=italiano\&id=704\& area=influenza\&menu=vuoto (accessed on 18 February 2020).

9. Peasah, S.K.; Azziz-Baumgartner, E.; Bresee, J.; Meltzer, M.I.; Widdowson, M.A. Influenza cost and cost-effectiveness studies globally - A review. Vaccine 2013, 31, 5339-5348. [CrossRef] [PubMed]

10. De Francisco Shapovalova, N.; Donadel, M.; Jit, M.; Hutubessy, R. A systemmatic review of the social and economic burden of influenza in low- and middle-income countries. Vaccine 2015, 33, 6537-6544. [CrossRef]

11. Bartolozzi, G. Vaccini e Vaccinazioni; Masson, E., Ed.; Elsevier: Amsterdam, the Netherlands, 2012.

12. Ministero della Salute. Dati Coperture Vaccinali. Available online: http://www.salute.gov.it/portale/influenza/ dettaglioContenutiInfluenza.jsp?lingua=italiano\&id=679\&area=influenza\&menu=vuoto (accessed on 18 February 2020).

13. Bridges, C.B.; Kuehnert, M.J.; Hall, C.B. Transmission of influenza: Implications for control in health care settings. Clin. Infect. Dis. 2003, 37, 1094-1101.

14. World Health Organization. Pandemic Influenza Risk Management: A WHO Guide to Inform and Harmonize National and International Pandemic Preparedness and Response. Available online: https://apps.who.int/iris/bitstream/handle/10665/259893/WHO-WHE-IHM-GIP-2017.1-eng. pdf?sequence $=1$ \&isAllowed $=y$ (accessed on 18 February 2020).

15. Gentili, D.; Bardin, A.; Ros, E.; Piovesan, C.; Ramigni, M.; Dalmanzio, M.; Dettori, M.; Filia, A.; Cinquetti, S. Impact of Communication Measures Implemented During a School Tuberculosis Outbreak on Risk Perception among Parents and School Staff, Italy, 2019. Int. J. Environ. Res. Public Health 2020, 17, 911. [CrossRef]

16. Sandman, P. Outrage Prediction and Management. Available online: http://www.psandman.com/handouts/ sand58.pdf (accessed on 15 September 2018). 
17. World Health Organization. Outbreak Communication: Best Practices for Communicating with the Public during an Outbreak: Report of the WHO Expert Consultation on Outbreak Communications held in Singapore, 21-23 September 2004. 2004. Available online: https://apps.who.int/iris/handle/10665/69138 (accessed on 30 January 2020).

18. Rubin, G.J.; Amlôt, R.; Pege, L.; Wessely, S. Public perceptions, anxiety, and behaviour change in relation to the swine flu outbreak: Cross sectional telephone survey. BMJ 2009, 339, b2651. [CrossRef]

19. Smith, R.D. Responding to global infectious disease outbreaks: Lessons from SARS on the role of risk perception, communication and management. Soc. Sci. Med. 2006, 63, 3113-3123. [CrossRef]

20. Tumpey, A.J.; Daigle, D.; Nowak, G. Communicating During an Outbreak or Public Health Investigation, CDC, Epidemic Intelligence Service. Available online: https:/www.cdc.gov/eis/field-epi-manual/chapters/ \%20Communicating-Investigation.html (accessed on 30 January 2020).

21. Dettori, M.; Arru, B.; Azara, A.; Piana, A.; Mariotti, G.; Camerada, M.V.; Stefanelli, P.; Rezza, G.; Castiglia, P. In the Digital Era, Is Community Outrage a Feasible Proxy Indicator of Emotional Epidemiology? The Case of Meningococcal Disease in Sardinia, Italy. Int. J. Environ. Res. Public Health 2018, 15, 1512. [CrossRef] [PubMed]

22. Azara, A.; Dettori, M.; Castiglia, P.; Piana, A.; Durando, P.; Parodi, V.; Salis, G.; Saderi, L.; Sotgiu, G. Indoor Radon Exposure in Italian Schools. Int. J. Environ. Res. Public Health 2018, 15, 749. [CrossRef] [PubMed]

23. Dettori, M.; Azara, A.; Loria, E.; Piana, A.; Masia, M.D.; Palmieri, A.; Cossu, A.; Castiglia, P. Population Distrust of Drinking Water Safety. Community Outrage Analysis, Prediction and Management. Int. J. Environ. Res. Public Health 2019, 16, 1004. [CrossRef] [PubMed]

24. Carducci, A.L.; Fiore, M.; Azara, A.; Bonaccorsi, G.; Bortoletto, M.; Caggiano, G.; Calamusa, A.; De Donno, A.; De Giglio, O.; Dettori, M.; et al. Environment and health: Risk perception and its determinants among Italian university students. Sci. Total Environ. 2019, in press. [CrossRef]

25. Larson, H.J.; Jarrett, C.; Eckersberger, E.; Smith, D.M.; Paterson, P. Understanding vaccine hesitancy around vaccines and vaccination from a global perspective: A systematic review of published literature, 2007-2012. Vaccine 2014, 32, 2150-2159. [CrossRef]

26. Opel, D.J.; Taylor, J.A.; Mangione-Smith, R.; Solomon, C.; Zhao, C.; Catz, S.; Martin, D. Valid-ity and reliability of a survey to identify vaccine-hesitant parents. Vaccine 2011, 29, 6598-6605. [CrossRef]

27. SAGE Working Group on Vaccine Hesitancy. Available online: http://www.who.int/\%20immunization/sage/ sage\%20wg\%20vaccine\%20hesitancy\%20apr12/en/ (accessed on 19 February 2020).

28. Dube, E.; Gagnon, D.; Nickels, E.; Jeram, S.; Schuster, M. Mapping vaccine hesitancy-country-specific characteristics of a global phenomenon. Vaccine 2014, 32, 6649-6654. [CrossRef]

29. La Torre, G.; Miccoli, S.; Ricciardi, W. The Italian alliance for vaccination strategies: Facebook as a learning tool for preventive medicine and public health. Hum. Vaccines Immunother. 2014, 10, 2910-2914. [CrossRef]

30. Karafillakis, E.; Dinca, I.; Apfel, F.; Cecconi, S.; Wûrz, A.; Takacs, J.; Suk, J.; Celentano, L.P.; Kramarz, P.; Larson, H.J. Vaccine hesitancy among healthcare workers in Europe: A qualitative study. Vaccine 2016, 34, 5013-5020. [CrossRef]

31. Betsch, C. Opportunities and challenges of Web 2.0 for vaccination decisions. Vaccine 2012, 30, 3727-3733. [CrossRef]

32. Stockwell, M.S.; Fiks, A.G. Utilizing health information technology to improve vaccine communication and coverage. Hum. Vaccines Immunother. 2013, 8, 1802-1811. [CrossRef] [PubMed]

33. Advisory Committee on Immunization Practices; Centers for Disease Control and Prevention (CDC). Immunization of health-care personnel: Recommendations of the Advisory Committee on Immunization Practices (ACIP). MMWR Recomm. Rep. 2011, 60, 1-45.

34. Gruppo di Studio Conferenza Nazionale "Medice cura te ipsum". La Carta di Pisa delle vaccinazioni negli operatori sanitari. The Pisas' Paper of Vaccinations in Healthcare Professionals, Pisa il, Italy, 27-28 March 2017; Available online: https://gimpios.it/r.php?v=2904\&a=29262\&l=334060\&f=allegati/02904_2017_04/fulltext/ 155-157_CartaPisa.pdf (accessed on 2 May 2020).

35. CDC. Influenza (Flu). CDC Recommends. Available online: https://www.cdc.gov/flu/prevent/different-fluvaccines.htm (accessed on 18 February 2020).

36. CDC. Healthcare Infection Control Practices Advisory Committee (HICPAC). Available online: https: //www.cdc.gov/flu/professionals/infectioncontrol/healthcaresettings.htm (accessed on 18 February 2020). 
37. Galanakis, E.; Jansen, A.; Lopalco, P.L.; Giesecke, J. Ethics of mandatory vaccination for healthcare workers. EuroSurveillance 2013, 18, 20627. Available online: http://www.eurosurveillance.org/ViewArticle.aspx? ArticleId=20627 (accessed on 30 January 2020). [CrossRef] [PubMed]

38. Worksite: Seasonal Influenza Vaccinations Using Interventions with On-Site, Free, Actively Promoted Vaccinations-Healthcare Workers. Available online: https://www.healthypeople.gov/2020/tools-resources/ evidence-based-resource/worksite-seasonal-influenza-vaccinations-using (accessed on 30 January 2020).

39. World Health Organization. How to Implement Seasonal Influenza Vaccination of Health Workers. Available online: https://apps.who.int/iris/rest/bitstreams/1238564/retrieve (accessed on 28 February 2020).

40. Ministero della Salute. Prevenzione e Controllo dell'Influenza: Raccomandazioni per la stagione 2019-2020. Available online: http://www.salute.gov.it/portale/influenza/dettaglioContenutiInfluenza.jsp? lingua=italiano\&id=685\&area=influenza\&menu=vuoto (accessed on 30 January 2020).

41. Ministero della Salute. Piano Nazionale di Prevenzione Vaccinale 2017-2019. Available online: http://www.salute.gov.it/portale/vaccinazioni/dettaglioContenutiVaccinazioni.jsp?lingua=italiano\&id= $4828 \& a r e a=$ vaccinazioni\&menu=vuoto (accessed on 30 January 2020).

42. Azienda Ospedaliero Universitaria di Sassari. Atto Aziendale. 2017. Available online: https://www.

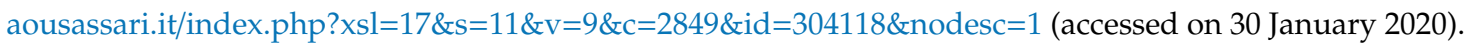

43. Mannocci, A.; Ursillo, P.; Bontempi, C.; Sferrazza, A.; La Torre, G. Prevalence of influenza vaccination among physicians and related enhancing and preventing factors in Italy. Rev. Health Care 2010, 1, 23-30. [CrossRef]

44. La Torre, G.; Mannocci, A.; Ursillo, P.; Bontempi, C.; Firenze, A.; Panico, M.G.; Sferrazza, A.; Ronga, C.; D'Anna, A.; Amodio, E.; et al. Prevalence of influenza vaccination among nurses and ancillary workers in Italy: Systematic review and meta analysis. Hum. Vaccines 2011, 7, 728-733. [CrossRef]

45. Seasonal Influenza Vaccination and Antiviral Use in EU/EEA Member States. Technical Report. Available online: https://www.ecdc.europa.eu/en/publications-data/seasonal-influenza-vaccination-antiviraluse-eu-eea-member-states (accessed on 18 February 2020).

46. Maltezou, H.C.; Poland, G.A. Vaccination policies for healthcare workers in Europe. Vaccine 2014, 32, 4876-4880. [CrossRef]

47. Alicino, C.; Iudici, R.; Barberis, I.; Paganino, C.; Cacciani, R.; Zacconi, M.; Battistini, A.; Bellina, D.; Di Bella, A.M.; Talamini, A.; et al. Influenza vaccination among healthcare workers in Italy. Hum. Vaccines Immunother. 2015, 11, 95-100. [CrossRef]

48. Hollmeyer, H.; Hayden, F.; Mounts, A.; Buchholz, U. Review: Interventions to increase influenza vaccination among healthcare workers in hospitals. Influenza Other Respir. Viruses 2013, 7, 604-621. [CrossRef]

49. Sartor, C.; Tissot-Dupont, H.; Zandotti, C.; Martin, F.; Roques, P.; Drancourt, M. Use of a mobile cart influenza program for vaccination of hospital employees. Infect. Control. Hosp. Epidemiol. 2004, 25, 918-922. [CrossRef]

50. Leitmeyer, K.; Buchholz, U.; Kramer, M.; Schenkel, K.; Stahlhut, H.; Köllstadt, M.; Haas, W.; Meyer, C. Influenza vaccination in German health care workers: Effects and findings after two rounds of a nationwide awareness campaign. Vaccine 2006, 24, 7003-7008. [CrossRef]

51. Doebbeling, B.N.; Edmond, M.B.; Davis, C.S.; Woodin, J.R.; Zeitler, R.R. Influenza vaccination of health care workers: Evaluation of factors that are important in acceptance. Prev. Med. 1997, 26, 68-77. [CrossRef]

52. Liu, H.; Tan, Y.; Zhang, M.; Peng, Z.; Zheng, J.; Qin, Y.; Guo, Z.; Yao, J.; Pang, F.; Ma, T.; et al. An Internet-Based Survey of Influenza Vaccination Coverage in Healthcare Workers in China, 2018/2019 Season. Vaccines 2019, 26, 8. [CrossRef] [PubMed]

53. De Juanes, J.R.; Garcia, D.C.; Arrazola, M.P.; Jaen, F.; Sanz, M.I.; Gonzalez, A. Influenza vaccination coverage among hospital personnel over three consecutive vaccination campaigns (2001-2002 to 2003-2004). Vaccine 2007, 25, 201-204. [CrossRef] [PubMed]

54. Valour, F.; Maulin, L.; Ader, F.; Perpoint, T.; Champagne, H.; David, G.; Boibieux, A.; Biron, F.; Peyramond, D.; Chidiac, C. Vaccination against influenza: Results of a study on vaccination coverage among health care workers in the Croix-Rousse Hospital (Hospitals of Lyon). Med. Mal. Infect. 2007, 37, 51-60. [CrossRef] [PubMed]

55. Gabutti, G.; Conforti, G.; Tomasi, A.; Kuhdari, P.; Castiglia, P.; Prato, R.; Memmini, S.; Azzari, C.; Rosati, G.V.; Bonanni, P. Why, when and for what diseases pregnant and new mothers "should" be vaccinated. Hum. Vaccines Immunother. 2017, 13, 283-290. [CrossRef] [PubMed]

56. Dharmapalan, D. Influenza. Indian J. Pediatr. 2020. [CrossRef] [PubMed] 
57. Koivula, A.; Räsänen, P.; Sarpila, O. Examining Social Desirability Bias in Online and Offline Surveys. Lect. Notes Comput. Sci. 2019, 145-158. [CrossRef]

58. Ricco', M.; Vezzosi, L.; Gualerzi, G.; Balzarini, F.; Capozzi, V.A.; Volpi, L. Knowledge, attitudes, beliefs and practices of obstetrics-gynecologists on seasonal influenza and pertussis immunizations in pregnant women: Preliminary results from North-Western Italy. Minerva Ginecol. 2019, 71, 288-297. [CrossRef]

59. Masia, M.D.; Solinas, G.; Piana, A.; Dettori, M.; Sotgiu, G.; Castiglia, P. Smoking habit and behaviour among health professionals. Annali di Igiene 2006, 18, 261-269.

60. Riccò, M.; Cattani, S.; Casagranda, F.; Gualerzi, G.; Signorelli, C. Knowledge, attitudes, beliefs and practices of Occupational Physicians towards seasonal influenza vaccination: A cross-sectional study from North-Eastern Italy. J. Prev. Med. Hyg. 2017, 58, E141-E154.

61. \#PerchéSì: Sassari Wins Award for Best Project in Italy. Available online: https:/www.vaccinarsinsardegna.org/ en/notizie/2019/10/premiato-sassari-miglior-progetto-comunicazione-vaccinale (accessed on 30 April 2020).

(C) 2020 by the authors. Licensee MDPI, Basel, Switzerland. This article is an open access article distributed under the terms and conditions of the Creative Commons Attribution (CC BY) license (http://creativecommons.org/licenses/by/4.0/). 